УдК 37.013

\title{
СОВРЕМЕННЫЕ ПОДХОДЫ К ОРГАНИЗАЦИИ ЭАЕКТРОННОГО ОБУЧЕНИЯ ДЕТЕЙ НА ОСНОВЕ ОПЫТА ДИСТАНЦИОННОЙ ШКОАЫ ПРИ НИЯУ МИФИ
}

\author{
С.А. Филиппов, к.т.н. (Институт проблем информатики РАН, ул. Вавилова, 44, к. 2, г. Москва, \\ 119333, Россия; Национальный исследовательский ядерный университет "МИФИ", Каширское ш., 31, \\ 2. Москва, 115409, Россия, ipiran@ipiran.ru)
}

Аннотация. Представлены четыре подхода к организации электронного обучения детей, основанные на расширении общеобразовательных программ старшей школы за счет использования современных информационных технологий и организации единого сетевого пространства.

Ключевые слова: дистанционное обучение, электронное обучение, подходы к созданию систем обучения, индивидуальная траектория обучения, подготовка преподавателей, тьюторы.

Сегодня как никогда важным является вопрос разработки и внедрения моделей взаимодействия учреждений высшего профессионального и общего образования по реализации общеобразовательных программ старшей школы, ориентированных на развитие интереса у детей и подростков к определенным наукам.

Первый подход к обучению детей базируется на комбинировании в одном образовательном процессе форм очного и заочного обучения. Основной идеей, на которой базируется подход, является расширение аудиторных рамок за счет технических средств коммуникаций, что наилучшим образом отвечает задачам преподавания предметов естественно-научного цикла, позволяет предоставлять школьникам для изучения материал, который по объективным причинам невозможно изучать на уроках в рамках стандартного образовательного процесса. Подход предусматривает очные сессии, в ходе которых обучение ведется преподавателями вуза. Школьникам предоставляется возможность получать необходимые консультации по предметам, пользоваться литературой из библиотечного фонда, предметными кабинетами для проведения практических и лабораторных работ. В межсессионный период преподаватели ведут занятия в виртуальных классах с удаленными учащимися. Ученики из разных школ обучаются у одного или нескольких преподавателей, причем учащимся обеспечивается удаленный доступ к необходимым учебным материалам и справочным пособиям.

Таким образом, предложенный подход позволяет решать следующие задачи:

- создание системы работы с детьми, сочетающей в себе преимущества очного и заочного обучения;

- создание условий для индивидуальной самореализации и развития детей посредством виртуального методического сопровождения обучающихся и педагогов;

- обеспечение технической и методической поддержки внедрения и развития дистанционных технологий в процессе обучения детей;

- обеспечение доступности для детей (прежде всего сельских районов) различных вариантов специализированной подготовки к предметным олимпиадам.

Таким образом, подход подразумевает создание сетевого объединения вуза, школ-партнеров, команд преподавателей и детей (см. рис. 1). 


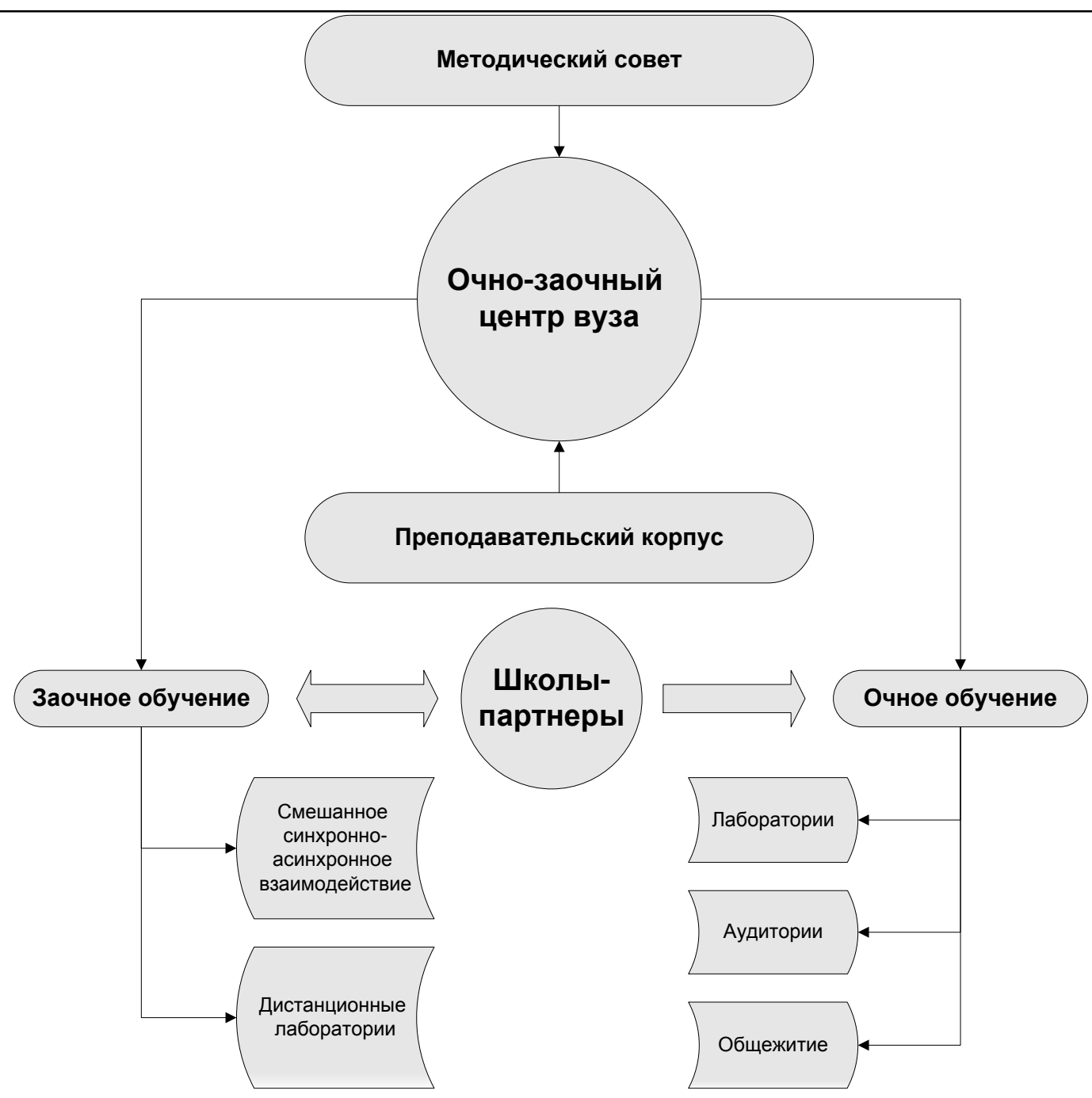

Рис. 1. Очно-заочный подход

Второй подход направлен на решение проблем обучения предметам гуманитарной направленности, специфика которых отличается от специфики точных наук. Необходимо помнить, что каждый ребенок в будущем способен достичь выдающихся успехов в той или иной области, поэтому особенно важно вести работу по развитию у детей качественно высокого уровня мировоззренческих убеждений, позволяющих им ориентироваться в сложном мире социальных отношений, добиваться формирования духовного потенциала личности ребенка, ее развития, направленного на творческое самовыражение и самореализацию. В рамках обучения гуманитарным дисциплинам необходимо развивать в детях умение в обширном потоке информации отделять важное от второстепенного, поощрять склонность к проведению глубокой мыслительной, исследовательской работы, добиваться формирования собственного взгляда на многие актуальные проблемы. Поэтому второй подход основывается на создании на базе вуза уникального ресурсного центра, обеспеченного банком эксклюзивных материалов, позволяющих детям развивать свои таланты на дополнительном и редко встречающемся, но особенно привлекательном материале. Занятия, проводимые в рамках данного подхода, также могут дополнять существующие школьные программы по таким предметам, как история или культурология, но они, основываясь на проектном методе работы, отличаются от стандартной программы возможностью проводить самостоятельные тематические исследования, готовить творческие рефераты, защищать и обосновывать свою точку зрения. Данный подход также ориентирован на сетевое взаимодействие педагогов и учащихся и на- 
правлен на развитие и укрепление культурного потенциала детей. На рисунке 2 показаны взаимосвязи субъектов при реализации эксклюзивного подхода.

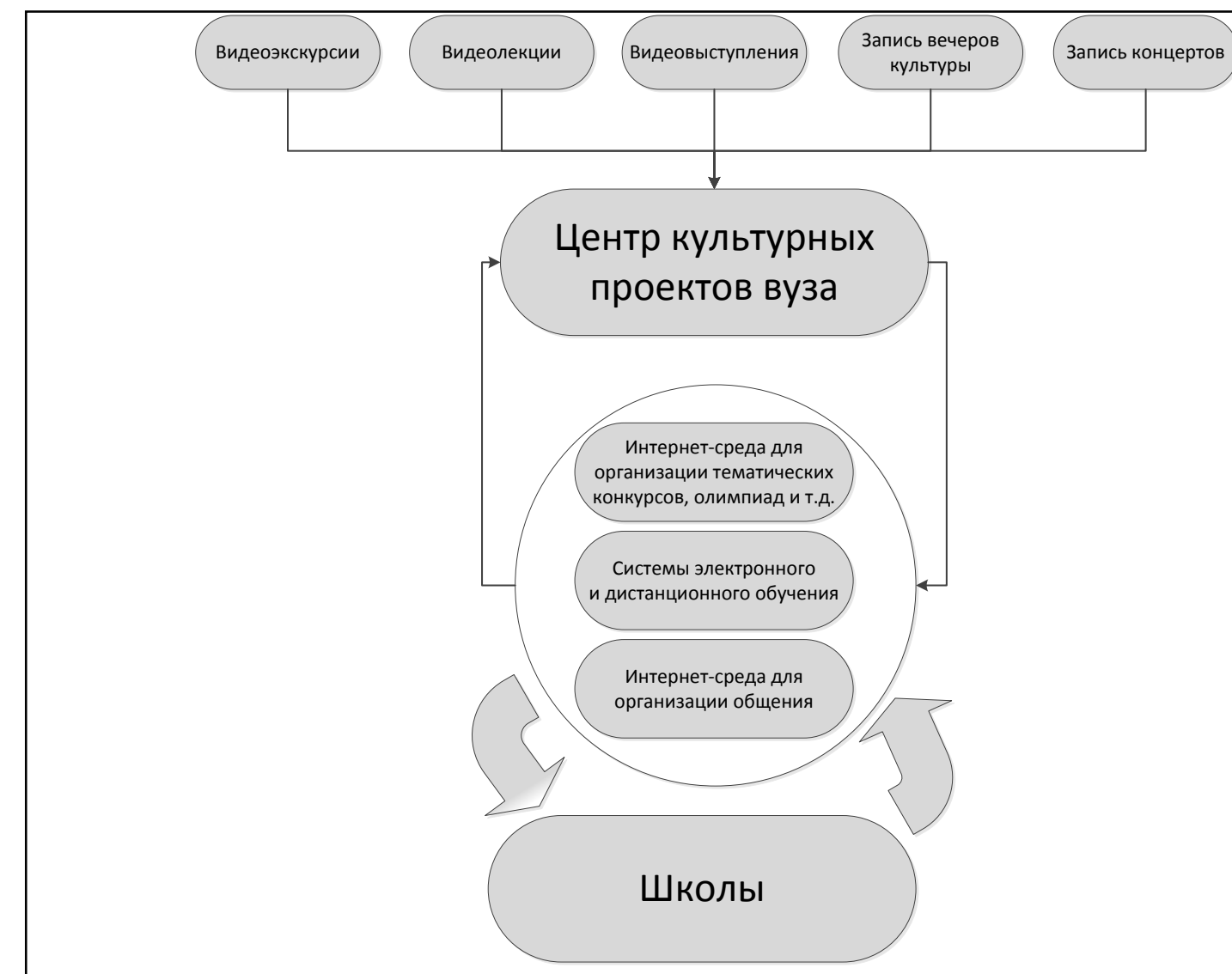

Рис. 2. Взаимосвязи субъектов при реализации эксклюзивного подхода

Одной из серьезных проблем российского образования на современном этапе является существенное ослабление естественно-научной и технической составляющих школьного образования, как основного, так и дополнительного, внеклассного. Это приводит к тому, что среди молодежи престижность инженерных профессий, без которых по-прежнему немыслимо существование общества, падает с каждым годом. Для эффективной работы в профессиональном образовании, начиная с общеобразовательной школы, необходимы популяризация и углубленное изучение естественно-технических дисциплин, развитие детского технического творчества и формирование инженерного мышления. Однако дополнительное техническое образование (различные технические кружки: авто- и авиамоделирования, судостроения и т.д.) достаточно сложно перестраивается в условиях научно-технического прогресса. Материальная база и учебные программы многих станций юных техников морально и физически устарели. Третий подход в электронном обучении детей и призван решить эту проблему. Как и второй, гуманитарный, он позволяет ориентировать школьников на дополнительное, углубленное изучение таких дисциплин, как конструирование (проектирование), программирование, моделирование и т.п. В результате проводимой профориентационной работы школьники получают полезные навыки, необходимые им в повседневной жизни, учатся мыслить логически, продумывать всю технологическую цепочку, искать возникающие ошибки и добиваться нужного результата.

Основной задачей вуза в указанном подходе является создание виртуального пространства, в котором сформированное по особым принципам сетевое сообщество получает возможность и стимулы для совместного обучения, обсуждения актуальных проблем предметной области, наработки и демонстрации достижений 
учащихся из разных регионов страны в области технического творчества. Особую часть обсуждаемого пространства должна занимать база знаний, поддерживающая учебную, информационно-консультативную и методическую работу по выбранным направлениям. На рисунке 3 представлена сетевая структура предлагаемого подхода с ядром в виде Центра технического творчества, организованного в формате электронной площадки.

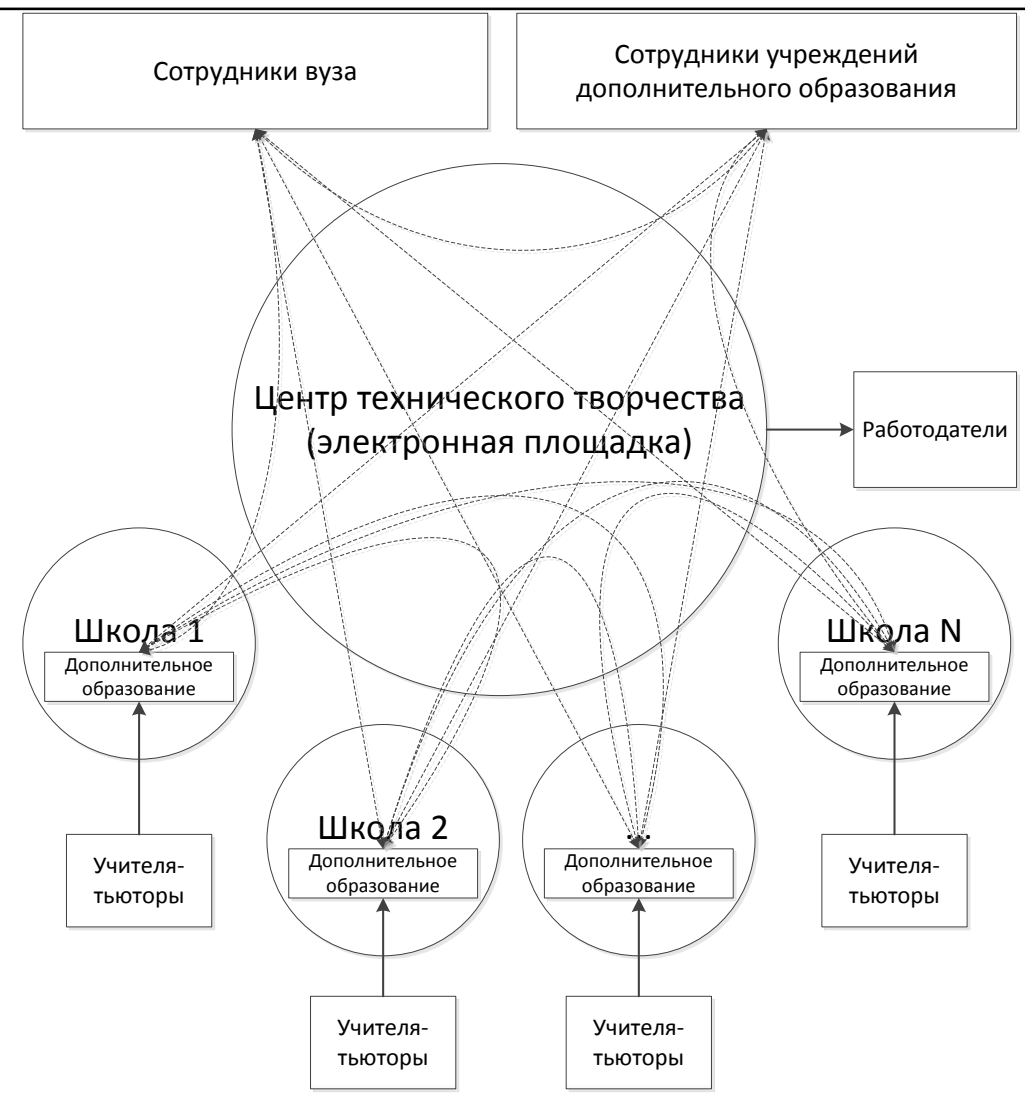

Рис. 3. Сетевая структура взаимодействия участников творческого процесса на базе электронной площчадки

Анализ мирового и российского опыта организации электронного обучения школьников показывает, что переход полностью на дистанционное взаимодействие, без использования очного обучения, для изучения предметов естественно-научного цикла неэффективен. В связи с тем, что школьники зачастую еще не освоили практику самообучения, им требуется некоторый переходный период перед интенсивной работой в рамках дистанционного образования. Причем самообразование и личностное самоопределение подразумевают проявление значительных волевых усилий, высокую степень сознательности и организованности, принятие внутренней ответственности за свой выбор, саморазвитие и самоопределение. Такая ситуация требует, чтобы выработке этих качеств личности у ребенка уделялось особое внимание на всех этапах обучения. Поэтому четвертый подход к электронному обучению в значительной мере направлен на подготовку наставников-тьюторов, которые непосредственно взаимодействуют с детьми в процессе обучения и помогают им справляться с возникающими трудностями. При этом тьюторы являются промежуточным звеном, взаимодействующим как с преподавателями вуза, ведущими занятия непосредственно в дистанционной школе, так и с самими школьниками. Данный подход лучше всего работает при реализации ступенчатой системы: на низшем, базовом, уровне с детьми работают преподаватели муниципальных образовательных учреждений; если ребенок демонстрирует достаточные успехи, он переходит на следующий уровень, средний, где с ним работают учителя-предметники уровня субъекта РФ; далее для наиболее одаренных учащихся предусмотрен 
третий, высший, уровень, на котором непосредственное руководство процессом обучения осуществляют преподаватели вуза, предварительно прошедшие обучение по специальной программе. Предусмотрено тесное взаимодействие между преподавателями на всех трех уровнях, для чего, в частности, организуется сетевое сообщество, помогающее учителям совместно решать профессиональные задачи.

Таким образом, все четыре описанных подхода являются взаимодополняющими и направлены прежде всего на предоставление детям и родителям дополнительных возможностей, позволяющих развить глубокую творческую личность и добиться существенных успехов в выбранном направлении деятельности.

\section{Литература}

1. Филиппов С.А. Организация дополнительного образования одаренных детей по информационным технологиям на базе дистанционной школы // Информатика и образование. 2012 . № 7 (236). С. 87-89.

2. Филиппов С.А., Комелина Е.В. Организация дистанционного обучения одаренных детей по модели «Очно-заочный центр» // Ученые записки: электр. науч. журн. Курского гос. ун-та. 2012. № 3 (23). T. 1. URL: http://scientific-notes.ru/pdf/025-024.pdf (дата обращения 12.03.2013).

3. Филиппов С.А., Комелина Е.В. Система подготовки педагогов к работе с одаренными детьми на основе современных информационных технологий // Вестн. Российского ун-та дружбы народов. Сер. Информатизация образования. 2013. № 1. С. 28-34. 